\title{
Determinants of tuberculin reactivity among health care workers: Interpretation of positivity following BCG vaccination
}

\author{
Andrew Mckay BScMed ${ }^{1}$, Allen Kraut MD FRCPC ${ }^{1,2,3,4}$, Carol Murdzak RN COHN ${ }^{4}$, \\ Annalee Yassi MD MSc FRCPC $1,2,3,4$
}

\begin{abstract}
A Mckay, A Kraut, C Murdzak, A Yassi. Determinants of tuberculin reactivity among health care workers: Interpretation of positivity following BCG vaccination. Can J Infect Dis 1999;10(2):134-139.

OBJECTIVE: To determine the extent to which a history of Bacille Calmette-Guerin (BCG) vaccination influences the likelihood of positive tuberculin skin test (TST) results.

DESIGN: Cross-sectional survey using a hospital-based tuberculosis surveillance program.

SETTING: Health Sciences Centre, a tertiary care hospital in Winnipeg, Manitoba.

METHODS: The 476 health care workers (HCWs) who had TST as part of the surveillance program between 1993 and 1997 constituted the study population. The two-step test was done in $91 \%$ of the participants who did not have a positive initial test, defined as $10 \mathrm{~mm}$ or greater of induration. Data were gathered through chart review supplemented by a short questionnaire administered to the HCWs.

MAIN RESULTS: One hundred and thirty-eight HCWs (29\%) had a positive TST. In a stepwise, multiple logistic model controlling for age, sex, job title, work area, age of receiving BCG, time since BCG and duration of employment, only a history of BCG vaccination (odds ratio [OR] 22; $95 \%$ CI 12 to 41) and birth outside of Canada (OR 2.6; $95 \%$ CI 1.4 to 5.8) were significantly associated with a positive TST. When the definition of a positive TST was modified by increments of $1 \mathrm{~mm}$, from $10 \mathrm{~mm}$ up to $20 \mathrm{~mm}$ of induration in BCG recipients, BCG was associated with positive reactions with indurations up to $19 \mathrm{~mm}$ but not $20 \mathrm{~mm}$ or greater. The OR declined with each increment. Of the $84 \mathrm{HCWs}$ who were documented to have at least 20 years between BCG vaccination and testing, 41 (49\%) had positive reactions.

CONCLUSIONS: BCG vaccination can produce lasting tuberculin reactivity, and indurations of $19 \mathrm{~mm}$ or less may be due to the effects of the vaccine.
\end{abstract}

Key Words: Bacille Calmette-Guerin vaccination, Epidemiology, Tuberculin skin test, Tuberculosis

Pour le résumé, voir page 135

\footnotetext{
${ }^{1}$ Faculty of Medicine; ${ }^{2}$ Department of Medicine; ${ }^{3}$ Department of Community Health Sciences, University of Manitoba; ${ }^{4}$ Health Sciences Centre, Winnipeg, Manitoba

Correspondence and reprints: Dr Allen Kraut, Departments of Medicine and Community Health Sciences, University of Manitoba, S112-750 Bannatyne Avenue, Winnipeg, Manitoba R3E OW3. Telephone 204-789-3294, fax 204-789-3905, e-mail akraut@ms.umanitoba.ca

Received for publication April 28, 1998. Accepted September 21, 1998
} 


\title{
Facteurs déterminant la réactivité à la tuberculine chez les travailleurs de la santé : Interprétation des résultats positifs au vaccin BCG
}

\begin{abstract}
OBJECTIF : Déterminer à quel point le vaccin BCG influe sur les risques que les résultats du test cutané à la tuberculine soient positifs.

MODÈLE : Enquête transversale menée par l'entremise d'un programme de surveillance épidémiologique hospitalière de la tuberculose.

CONTEXTE : Health Sciences Centre, hôpital de soins tertiaires de Winnipeg au Manitoba.

MÉTHODES : Les 476 travailleurs de la santé qui ont subi un test à la tuberculine dans le cadre d'un programme épidémiologique entre 1993 et 1997 formaient la population étudiée. Le test en deux étapes a été effectué chez $91 \%$ des participants qui n'avaient pas eu de résultat positif au test initial, défini comme une induration de $10 \mathrm{~mm}$ ou plus. Les données ont été recueillies dans les dossiers et par la compilation d'un bref questionnaire administré aux travailleurs de la santé.

PRINCIPAUX RÉSULTATS : Cent trente huit travailleurs de la santé (29\%) ont obtenu des résultats positifs au test à la tuberculine. Dans un modèle logistique multiple par étapes tenant compte de l'âge, du sexe, du type de poste, du lieu de travail, de l'âge au moment de la vaccination, du temps écoulé depuis le BCG et depuis l'arrivée à ce poste, seuls le vaccin BCG (risque relatif [RR]22; IC $95 \% 12$ à 41) et le fait d'être né à l'extérieur du Canada (RR 2,6; IC $95 \% 4$ à 5,8) se sont révélés significativement associés à des résultats positifs au test à la tuberculine. Lorsque la définition d'un test positif à la tuberculine a été modifiée par tranche de $1 \mathrm{~mm}$ à partir de $10 \mathrm{~mm}$ jusqu'à $20 \mathrm{~mm}$ d'induration chez les sujets ayant reçu le vaccin BCG, ce dernier a été associé à des réactions positives, avec des indurations allant jusqu'à $19 \mathrm{~mm}$, mais non au-delà de $20 \mathrm{~mm}$. Le RR a décliné avec chaque tranche d'augmentation. Parmi les 84 travailleurs de la santé chez qui on a documenté un intervalle d'au moins 20 ans entre le vaccin BCG et le test, 41 (49\%) présentaient des réactions positives.

CONCLUSIONS : Le vaccin BCG peut entraîner une réactivité durable à la tuberculine et les indurations de $19 \mathrm{~mm}$ ou moins peuvent être attribuables aux effets du vaccin.
\end{abstract}

$\mathrm{O}$ ccupational exposure to tuberculosis (TB) is a recognized hazard among health care workers (HCWs). This risk of exposure had declined substantially for many years but is rising again (1). There are several reasons for this growing risk, depending on local conditions, including the resurgence of the disease, increased immigration from high prevalence countries, emergence of multidrug-resistant strains and the AIDS epidemic $(1,2)$. Occasionally, patients are admitted to hospital with TB that is initially unrecognized. Until their conditions are diagnosed and appropriate safety precautions are implemented, these patients represent a hazard to HCWs. Because of this hazard, the Laboratory Centre for Disease Control (3), the Canadian Thoracic Society (4) and the American Thoracic Society (ATS) (5) recommend that HCWs be given a tuberculin skin test (TST) to assess their TB infection status on hiring. Regular ongoing screening procedures for those working in areas designated as high risk and programs aimed at postexposure screening are also recommended.

The Health Sciences Centre (HSC), a tertiary care teaching hospital in the inner core of Winnipeg, Manitoba, serves as the TB referral hospital for the province. The Department of Occupational and Environmental Medicine (DOEM) administers TB screening programs at the hospital. New employees are screened for their tuberculin status, and there are two programs for ongoing surveillance. The first is an annual surveillance program of high-risk areas (including the microbiology laboratories, the morgue, the emergency department and respiratory wards). The second program is a contact follow-up program for HCWs who have had potential contact with patients with TB.

These screening programs are largely based on the interpretation of TSTs. However, not all persons with positive reactions are infected with Mycobacterium tuberculosis (6). One factor that causes difficulty in interpreting a TST is a previous Bacille Calmette-Guerin (BCG) vaccination (7). Interpretation of a TST in individuals with a history of BCG is an area of dispute. The ATS, the Centers for Disease Control and Prevention
(CDC) and others state that BCG vaccination does not lead to a sustained TST reactivity (6-8). For example, it has been suggested that BCG causes no more than 15 years of reactivity (7). Others, however, have stated that BCG vaccination may lead to much longer lasting reactivity $(2,9-11)$.

In Manitoba until the early 1980 s, it was common practice to provide $B C G$ vaccination to health care trainees before they began clinical exposures. Until 1993, it was DOEM policy not to perform TST on HCWs who had a history of BCG because it was thought that the vaccination might make the results of the test uninterpretable. Due to the controversy in interpreting TST in BCG recipients, this policy was changed, so that individuals who had a remote history of BCG vaccination would now have a TST.

The major objective of the present study was to determine whether a history of BCG influences TST reaction, and the circumstances, if any, under which BCG is a predictor of a positive TST. This information would assist the DOEM and other occupational health departments to determine whether HCWs with a history of BCG should receive a TST, and help clinicians in making their decisions on recommending prophylactic medication.

\section{SUBJECTS AND METHODS}

Between 1993 and 1997, 610 HCWs received a TST either as part of the screening program following potential contact with a TB patient or as part of the yearly screening program of individuals working in high-risk areas. Due to a history of a positive TST, 113 of these 610 people received a chest radiograph. The remaining 497 people received TST; 476 of these were included in the study group. Three hundred and fortyfive HCWs were identified through the contact follow-up program, and 131 through the regular surveillance program. The 21 people excluded consisted of 19 people with an unknown BCG history and another two who were 'old positives' and mistakenly retested (Figure 1).

Subjects were given a two-step TST (12), unless a two-step 


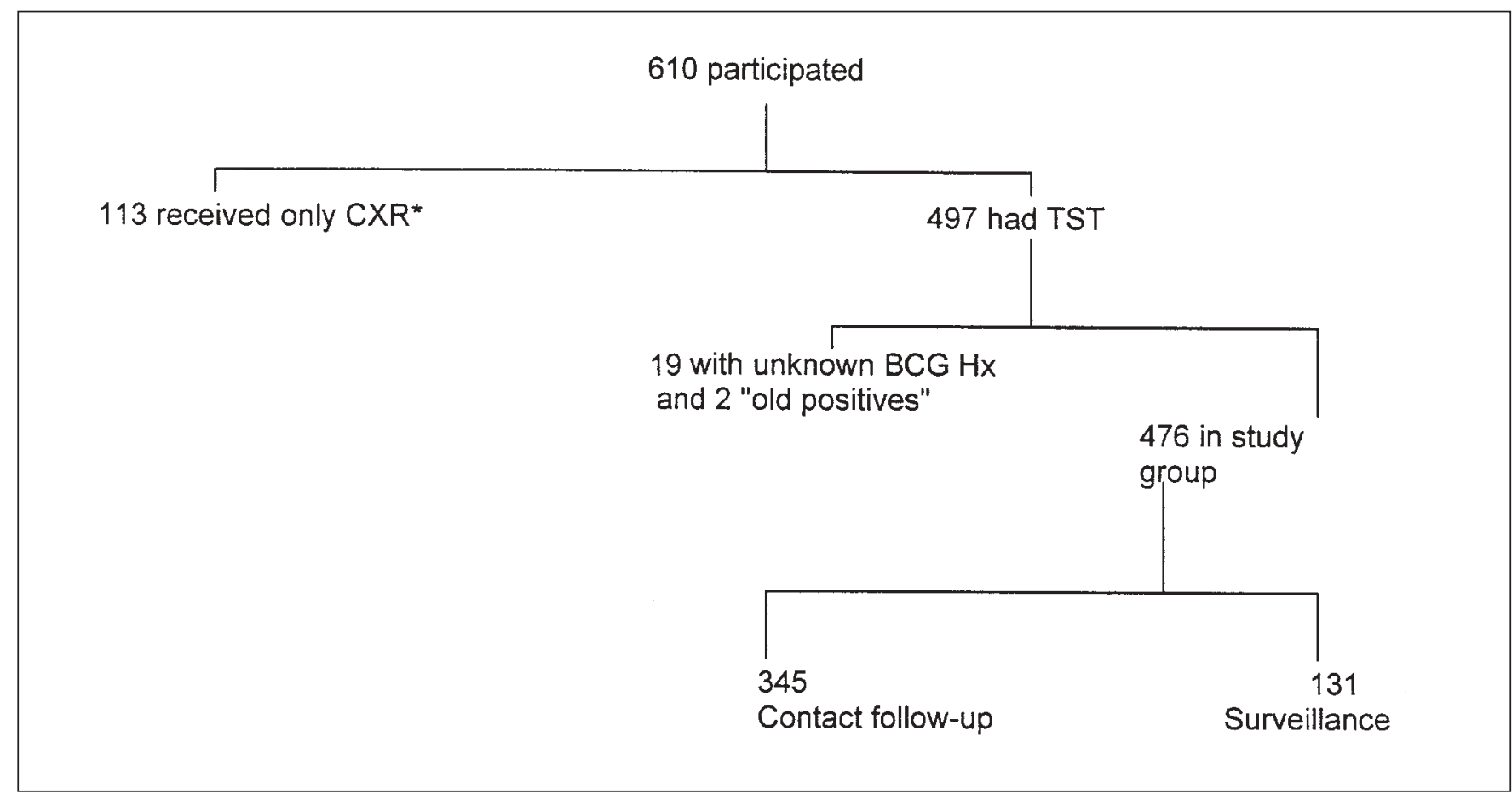

Figure 1) Identification of participants in the tuberculosis surveillance program at Health Science Centre, Winnipeg, Manitoba. *Known positive tuberculin skin test (TST) in the past. BCG Hx Bacille Calmette-Guerin history; CXR Chest radiograph

TABLE 1

Characteristics of $\mathbf{4 7 6}$ subjects in the tuberculosis surveillance program at Health Science Centre (HSC), Winnipeg, Manitoba

\begin{tabular}{lr}
\hline Variable & Total \\
\hline Age, years $(n=466)$ & $37 \pm 8$ \\
Sex $(n=476)$ & 392 \\
$\quad$ Female & 84 \\
$\quad$ Male & \\
BCG Status $(n=476)$ & 231 \\
$\quad$ BCG & 245 \\
$\quad$ No BCG & \\
Country of birth & 73 \\
$\quad$ Foreign & 278 \\
$\quad$ Canada & 125 \\
$\quad$ Not documented & $9 \pm 7$ \\
Years at HSC $(n=447)$ & $20 \pm 5$ \\
Age at BCG, years $(n=161)$ & $20 \pm 6$ \\
Years since BCG $(n=162)$ & \\
\hline
\end{tabular}

The majority of the 70 individuals who had a Bacille Calmette-Guerin (BCG) vaccination but for whom the age at the time of BCG is not known had their BCG as a child. $n$ The number of subjects with information documented for the particular category

test was documented in the past, in which case, only a single step was performed. Occupational health nurses conducted the testing following a standardized protocol. Subjects were injected with $0.1 \mathrm{~mL}$ ( 5 tuberculin units) of purified protein derivative (Tubersol, CT68 Connaught) on the volar surface of the upper forearm with standard tuberculin syringes. Reac- tions were read after $48 \mathrm{~h}$, and the transverse diameter of the area of induration was recorded in millimetres.

A reaction of $10 \mathrm{~mm}$ or greater on the first test was considered a positive reaction. Subjects with less than $10 \mathrm{~mm}$ induration on the initial test were given a repeat test one week later. Subjects with a reaction of $10 \mathrm{~mm}$ or more on the second test were classified as boosters. The total group of positive reactors comprised individuals who were positive on either test.

The employee medical records were examined, and information was gathered on past TST results, history of BCG vaccination, date of birth, country of birth, sex, the employee's jobs and work locations, and time employed at HSC. A questionnaire was distributed to gather information on country of birth, because this information had not been routinely recorded in the employee medical records. Arms and backs were also inspected for scars consistent with past BCG vaccinations. Table 1 details the study participants' characteristics. Work locations were divided into two large groups based on whether the individual worked in an area that was part of the annual screening program.

Data were entered into EPI INFO Version 6.0 (USD Inc, Georgia). Number Cruncher Statistical Software Version 5.0 (JL Hintze, Utah) was used to analyze the data. Stepwise multiple logistic regression was performed to identify predictors of a positive TST. History of BCG vaccination, time elapsed since BCG, age at time of BCG vaccination, age, foreign birth (Canadian, foreign and unknown), sex, work location and time employed at HSC were entered into the regression as independent variables. Odds ratios (ORs) with 95\% CIs were calculated. Missing data were dealt with in the following manner. When a 
TABLE 2

Number and percentage of subjects in the tuberculosis surveillance program with a positive tuberculin skin test univariate analysis

\begin{tabular}{lccc}
\hline Variable & Number tested & $\begin{array}{c}\text { Number } \\
\text { positive (\%) }\end{array}$ & $\begin{array}{c}\text { Odds ratio } \\
(\mathbf{9 5 \%} \mathbf{C I})\end{array}$ \\
\hline $\begin{array}{l}\text { Bacille Calmette-Guerin vaccination } \\
\quad \text { Yes }\end{array}$ & 231 & $126(55)$ & $23.0(12-44)$ \\
$\quad$ No & 245 & $12(5)$ & \\
$\begin{array}{l}\text { Country of birth } \\
\quad \text { Foreign }\end{array}$ & 73 & $39(53)$ & $3.6(2.1-6.2)$ \\
$\quad$ Canada & 278 & $67(24)$ & \\
Age & & & \\
$\quad 35$ years & 251 & $99(39)$ & $3.1(2.0-4.8)$ \\
$\quad<35$ years & 215 & $38(18)$ & \\
Sex & & & \\
$\quad$ Female & 392 & $120(31)$ & $1.6(0.9-2.8)$ \\
$\quad$ Male & 84 & $18(21)$ & \\
Total & 476 & $138(29)$ & \\
\hline
\end{tabular}

variable was found not to be significantly (ie, $\mathrm{P}$ 0.05) associated with a positive TST, the stepwise regression was repeated excluding this variable. During this analysis, individuals who had missing data for the variable in question were included. Missing country of birth data were also assessed, assuming that all individuals for whom this data were missing were either Canadian born or foreign born, creating a range that included the true value. Missing data for the second step of the two-step procedure were also assessed in this manner.

Because it has been reported that BCG causes smaller induration diameters than does exposure to $\mathrm{TB}(7)$, the influence of $B C G$ in subjects with larger induration diameters was also investigated. Analysis was repeated several times with the definition of a positive reaction for BCG recipients increasing in $1 \mathrm{~mm}$ increments from $10 \mathrm{~mm}$ until it became $20 \mathrm{~mm}$ or greater. For workers without a history of BCG vaccination, a positive reaction was defined as $10 \mathrm{~mm}$ or greater.

\section{RESULTS}

One hundred and thirty-eight subjects (29\%) had positive TSTs. The variable most strongly associated with a positive TST in univariate analysis was a history of BCG vaccination (OR 23; 95\% CI 12 to 44) (Table 2). Those born in foreign countries were almost four times more likely to have a positive TST (OR 3.6; 95\% Cl 2.1 to 6.2), and those over 35 years of age were three times as likely to be TST positive (OR 3.0; 95\% CI 2.0 to 4.7). Of 84 people who were documented to have at least 20 years between BCG vaccination and testing, 41 (49\%) had positive reactions; 59 of these individuals were Canadian born, eight were foreign born and the country of birth was unknown for 17.

Subjects were stratified by place of birth (Table 3). A strong association between BCG vaccination and tuberculin reactivity was observed, regardless of country of birth. This association was much stronger for Canadian-born subjects (OR 35; $95 \% \mathrm{CI} 12$ to 100) than for foreign-born subjects (OR 6.8; 95\%
TABLE 3

Odds ratios of a positive tuberculin skin test by Bacille

Calmette-Guerin (BCG) vaccination status, for

Canadian-born and foreign-born subjects in the tuberculosis surveillance program

\begin{tabular}{lccc}
\hline Status & Number tested & $\begin{array}{c}\text { Number } \\
\text { positive (\%) }\end{array}$ & $\begin{array}{c}\text { Odds ratio } \\
(\mathbf{9 5 \%} \text { CI) }\end{array}$ \\
\hline $\begin{array}{l}\text { Canadian born } \\
\text { BCG }\end{array}$ & 128 & $63(49)$ & $35(12-100)$ \\
$\quad$ No BCG & 150 & $4(3)$ & \\
$\begin{array}{l}\text { Foreign born } \\
\text { BCG }\end{array}$ & 51 & $34(67)$ & $6.8(2.1-22)$ \\
$\quad$ No BCG & 22 & $5(23)$ & \\
Country of birth not documented & & \\
$\quad$ BCG & 52 & $29(56)$ & $29(8.2-100)$ \\
$\quad$ No BCG & 73 & $3(4)$ & \\
Total & 476 & $138(29)$ & \\
\hline
\end{tabular}

CI 2.1 to 22). The OR for individuals whose country of birth was unknown equated the weighted average of those for whom the country of birth was known. This suggests that for the individuals for whom there were missing data, country of birth was distributed between Canada and foreign in a similar manner as for those whose country of origin was known.

To remove the confounding effect of BCG vaccination, the association between foreign birth and TST status was examined for subjects without a history of BCG vaccination (Table 4). A positive association between foreign birth and a positive TST was observed (OR 11; 95\% CI 2.6 to 44 ).

The results of the stepwise multiple logistic regression revealed that BCG vaccination (OR 22; $95 \% \mathrm{CI} 12$ to 41 ) and foreign birth (OR 2.6 ; $95 \%$ CI 1.4 to 5.8 ) were significantly associated with a positive TST. Nonsignificant variables were age, work area, time elapsed since BCG, age at time of BCG vaccination and sex. The OR for BCG vaccination was similar when all individuals whose country of birth was unknown were classified as either Canadian or foreign born.

Stepwise multiple logistic regression was also carried out for boosting, using the same variables. Only a history of a BCG had a significant association with boosting (OR 6.2; 95\% CI 1.9 to 19). If it was assumed that all 29 individuals who did not have the second step of the two-step procedure were positive, the OR would be 13 (95\% CI 10 to 15 ).

To assess the influence that BCG may have on TST size, analyses were repeated to examine the determinants of a positive reaction with a gradually increasing definition of a positive TST in BCG recipients. When a positive reaction was defined as $15 \mathrm{~mm}$ or greater, only BCG vaccination (OR 6.1; $95 \% \mathrm{CI} 3.1$ to 12 ) and foreign birth (OR 2.1; 95\% CI 1.1 to 3.9 ) were associated with positive reactions. The association with $B C G$ vaccination became less pronounced as larger induration sizes were used to define a positive test. At indurations of $20 \mathrm{~mm}$ or greater, BCG ceased to be a factor, and at this size, only foreign birth (OR 3.4; 95\% CI 1.7 to 7.1 ) was significantly 


\section{TABLE 4}

Odds ratio of a positive tuberculin skin test by place of birth, for subjects without Bacille Calmette-Guerin vaccination

\begin{tabular}{lccc}
\hline Variable $(\mathbf{9 5} \% \mathbf{C I})$ & Number tested & Positive (\%) & Odds ratio \\
\hline Birth & & & \\
$\quad$ Foreign & 22 & $5(23)$ & $11(2.6-44)$ \\
$\quad$ Canadian & 150 & $4(3)$ & 1.0 \\
Total & 172 & $9(5)$ & \\
\hline
\end{tabular}

associated with TST positivity. No other variable was significantly associated with positive reactions. The OR for positive TST with BCG vaccination and foreign birth according to induration size are shown in Figure 2.

\section{DISCUSSION}

Our finding that BCG vaccination is strongly associated with a positive tuberculin reaction is consistent with the results of a study of staff and residents of a nursing home (8). In our study, $55 \%$ of staff with a history of BCG had positive reactions compared with $5 \%$ of nonvaccinated staff. Multiple logistic regression revealed an OR for BCG of 22 . This finding is consistent with those of other reports $(2,9,10,13,14)$. The extremely high OR may be due to persistent reactivity among BCG recipients coupled with a low overall conversion rate. When induration diameters of $15 \mathrm{~mm}$ or greater are used to define a positive reaction for vaccinated subjects, the association with BCG is maintained, which is consistent with findings from other studies (14). We found BCG vaccinations to be associated with induration diameters of up to $19 \mathrm{~mm}$ on TST.

Our results suggest that BCG causes long-lasting positive TST reactions. The average time between vaccination and testing was $20 \pm 6$ years; $49 \%$ of those vaccinated at least 20 years before testing still had positive reactions. These results are consistent with those from a study from Spain that reported lasting reactivity to tuberculin in BCG vaccinated individuals for up to 25 years (14). An association between boosting and BCG was also observed, consistent with other data $(9,11,13)$.

Our findings do not support statements from the ATS, CDC and others who suggest that TST reactions in BCG recipients are often less than $10 \mathrm{~mm}$ in size and that sensitivity wanes with time $(6-8,15)$. Age at vaccination may influence the findings because vaccination in infancy is not related to tuberculin reactivity, while vaccination after five years of age is associated with TST reactions (16). This may help explain the discrepancies between our results and those of the CDC and ATS statements; our population consisted of a large proportion of HCWs who, for the vast majority, received their vaccinations upon entering the health care profession.

Consistent with other studies, positive TST reactions were associated with foreign birth $(2,17,18)$. A study of adult immigrants to the United States (17) reported that immigrants from regions with a low prevalence of $\mathrm{TB}$ who had received $\mathrm{BCG}$ vaccine were more likely to have a positive reaction than those who did not receive the vaccine. In that study, the association

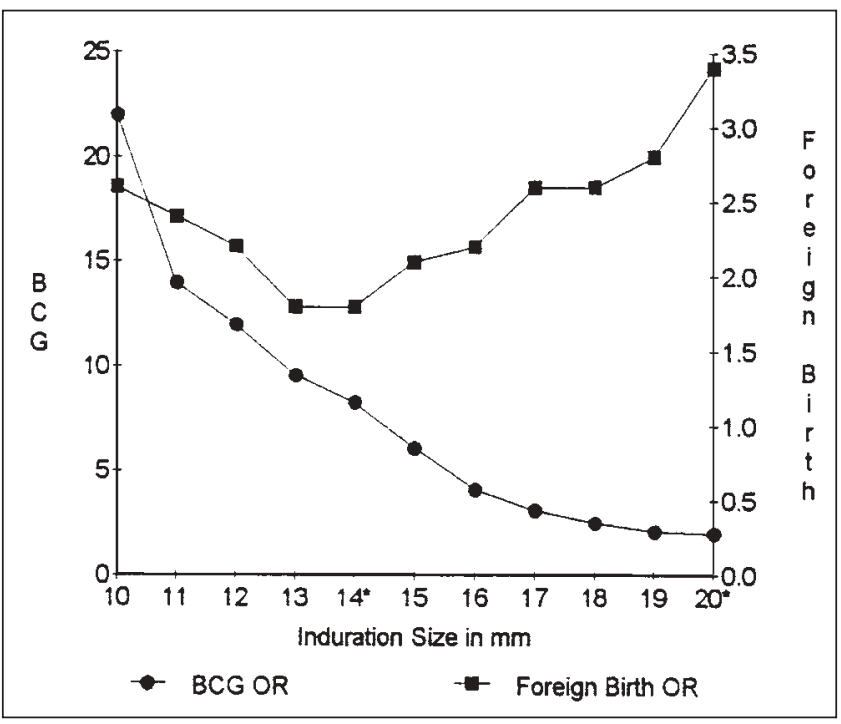

Figure 2) Odds ratios (OR) for Bacille Calmette-Guerin (BCG) vaccination and foreign birth. At $14 \mathrm{~mm}$ or greater induration, the OR for foreign birth (OR 1.8; 95\% CIO.97 to 3.3) was not significant; at $20 \mathrm{~mm}$ or greater induration, the OR for BCG (OR 2.0; 95\% CI 0.95 to 4.1) was not significant

between positive TST with BCG was not seen in immigrants from areas with a high prevalence of TB.

Foreign birth was associated with a positive TST in individuals without a history of BCG. These workers had a negative TST at hire, but usually this result was based on a one-step test. Thus, that foreign birth was still a predictor of a positive TST may be due to inadequate initial documentation.

Individuals working in the areas perceived as high risk (those undergoing annual screening) were no more likely to become TST positive than workers identified through contact follow-up. These findings suggest that the problem of TB exposure is not limited to certain designated high-risk areas of the hospital.

Time employed at HSC (in years) had no association with reactivity. However, this may not be a reliable indicator of occupational risk because this variable does not take into account actual time at work, changes in job classes or wards, and the amount of direct patient contact.

It has been previously documented that larger indurations reflect a greater chance of TB infection (7). Our findings that the association with $B C G$ decreased at larger indurations suggests that BCG vaccination can lead to TST measuring up to $19 \mathrm{~mm}$, but beyond that, positive TST is more likely related to TB exposure.

Until recently, the DOEM did not conduct TST on BCG recipients. It can be argued that the high rate of tuberculin positivity observed in this group is due to their having been infected with TB and not detected by screening until now, rather than being due to the effects of the vaccine. Evidence that disputes this suggestion is the disappearance of the association with BCG at larger induration diameters (ie, $20 \mathrm{~mm}$ or greater), which may be more predictive of TB exposure (7). Also, an association was not seen with time employed at the 
hospital, which may have been an indication that such undetected infection was occurring in this group.

A limitation to our study was that information was missing in some categories, most notably country of birth. To address this problem, we analyzed the data assuming that individuals whose country of birth was not known were all either Canadian or foreign born, and we also created an unknown country of birth category. The associations that we observed between positive TST and BCG were similar in all of these analyses.

The sample group was not random; it contained only people who have either undergone annual screening or who have had potential contact with TB. Although this may influence the percentage of positive reactors, it should not influence the association between a positive test and BCG.

\section{REFERENCES}

1. Menzies D, Fanning A, Yuan L, Fitzgerald M. Tuberculosis among health care workers. N Engl J Med 1995;332:92-8.

2. Horowitz HW, Luciano BB, Kadel JR, Wormser GP. Tuberculin skin test conversion in hospital employees vaccinated with bacille Calmette-Guerin: recent Mycobacterium tuberculosis infection or booster effect? Am J Infect Control 1995;23:181-7.

3. Health and Welfare Canada. Guidelines for preventing the transmission of tuberculosis in Canadian health care facilities and other institutional settings. Can Commun Dis Rep 1996;22:S1.

4. Canadian Thoracic Society Standards Committee (tuberculosis). Canadian Tuberculosis Standards, 4th edn. Gloucester: Canadian Lung Association, 1996.

5. American Thoracic Society. Control of tuberculosis. Am Rev Respir Dis 1983;128:336-42.

6. American Thoracic Society. The tuberculin skin test. Am Rev Respir Dis 1981;124:356-63.

7. Snider DE. Bacille Calmette-Guerin vaccinations and tuberculin skin tests. JAMA 1985;253:3438-9.

8. Use of BCG vaccinations in the control of tuberculosis. A joint statement by the ACIP and Advisory Committee for the Elimination of Tuberculosis. MMWR Morb Mortal Wkly Rep 1988;37:643-75

9. Rosenberg T, Manfreda J, Hershfield ES. Two-step tuberculin testing in staff and residents of a nursing home. Am Rev Respir Dis $1993 ; 148: 1537-40$.

\section{CONCLUSIONS}

Our results suggest that BCG vaccination leads to lasting TST reactivity and that reactions of $19 \mathrm{~mm}$ or less in BCG recipients may be due to the vaccine. For this reason, interpretation of a TST result of between $10 \mathrm{~mm}$ and $19 \mathrm{~mm}$ in a BCG recipient is difficult. In these instances, additional clinical data should be used when evaluating the need for prophylactic isoniazid treatment.

ACKNOWLEDGEMENTS: This project was supported in part by a grant from the Children's Hospital of Winnipeg Research Foundation. We thank the Children's Hospital of Winnipeg Research Foundation for their funding of this project and Ms Lisa Springer for assistance in manuscript preparation.

10. Langille DB, Sweet LE. Tuberculin skin testing in a hospital and two chronic care facilities in Prince Edward Island. Can J Infect Control 1995;10:41-4.

11. Sepulveda RL, Ferrer X, Latrach C, Sorensen RU. The influence of Calmette-Guerin Bacillus immunization on the booster effect of tuberculin testing in healthy young adults. Am Rev Respir Dis 1990;142:24-8.

12. MacMorran JL. Tuberculosis: A Handbook For Public Health Nurses and Other Interested Health Care Workers. Winnipeg: Department of Health, Manitoba, 1990.

13. Menzies R, Vissandjee B, Rocher I, St Germain Y. The booster effect in two-step tuberculin testing among young adults in Montreal. Ann Intern Med 1994;120:190-8.

14. Miret-Cuadras P, Pina-Gutierrez JM, Juncosa S. Tuberculin reactivity in Bacillus Calmette-Guerin vaccinated subjects. Tuberc Lung Dis 1995;77:52-8.

15. Johnson H, Doherty E, Kelly E, Mcdonnell T. Tuberculin sensitivity and the BCG scar in tuberculosis contacts. Tuberc Lung Dis 1995;76:122-5.

16. Menzies R, Vissandjee B. Effect of Bacille Calmette-Guerin vaccination on tuberculin reactivity. Am Rev Respir Dis 1992;145:621-5.

17. Ballew KA, Becker DM. Tuberculosis screening in adults who have received Bacille Calmette-Guerin vaccine. South Med J 1995;88:1025-30.

18. Rivest P, Tannenbaum T, Bédard L. Epidemiology of tuberculosis in Montreal. CMAJ 1998;158:605-9. 


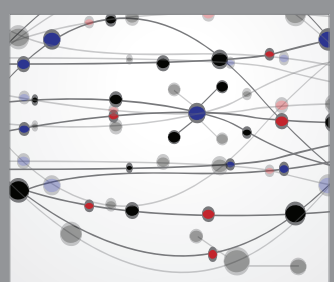

The Scientific World Journal
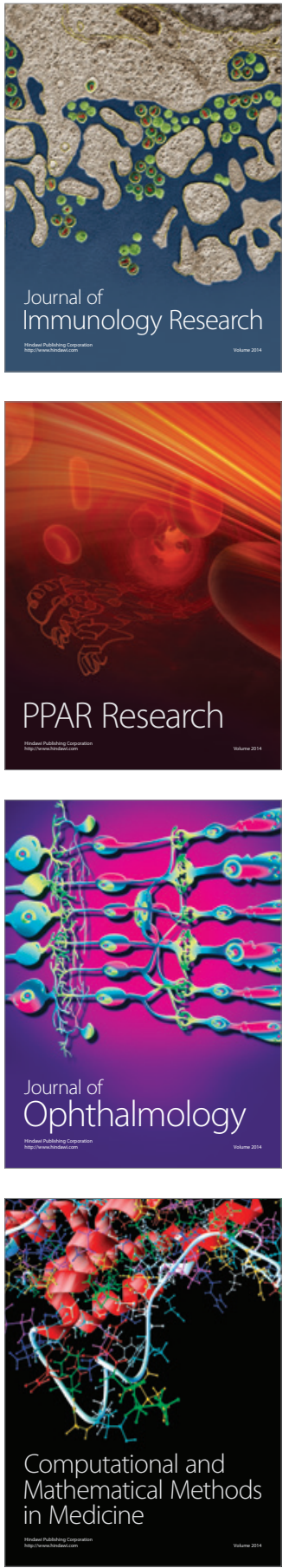

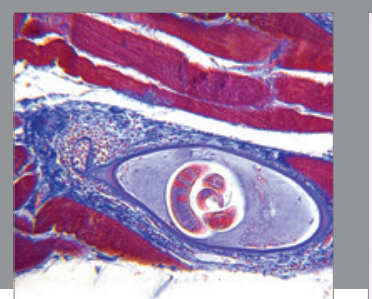

Gastroenterology Research and Practice

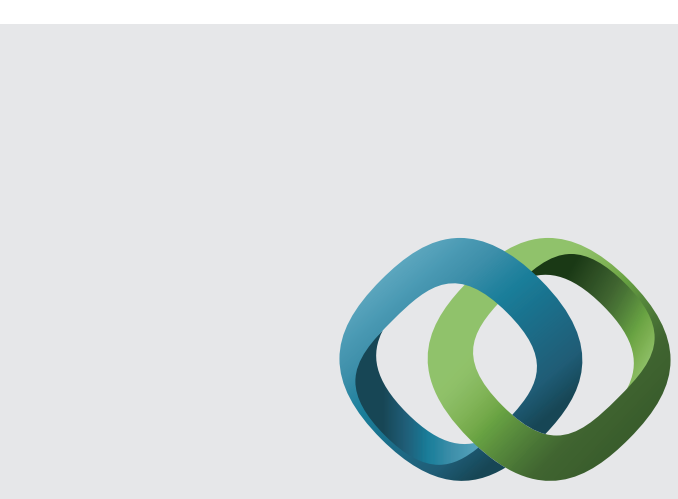

\section{Hindawi}

Submit your manuscripts at

http://www.hindawi.com
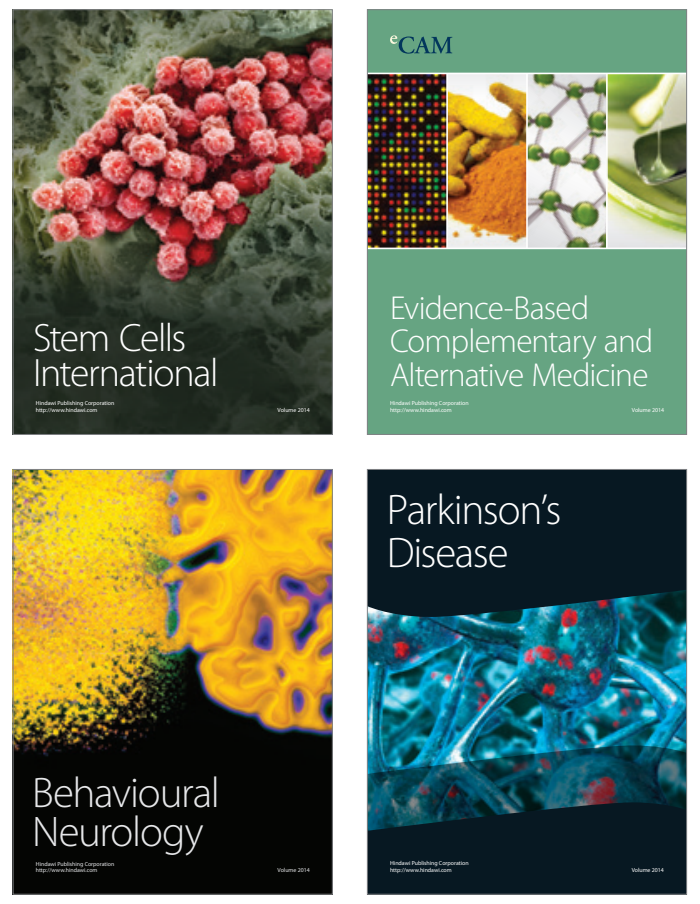
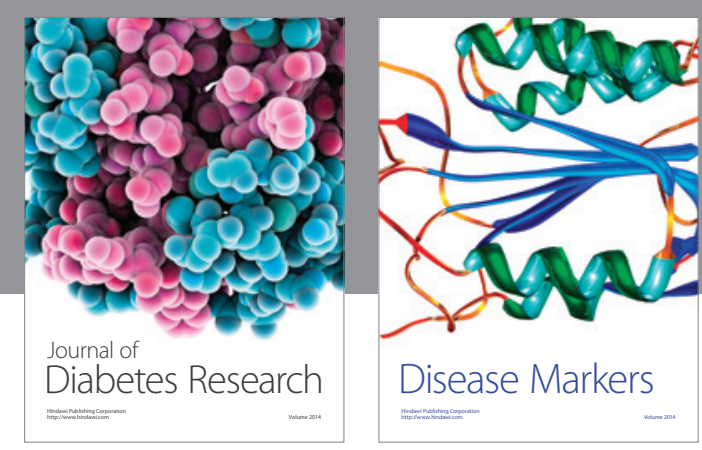

Disease Markers
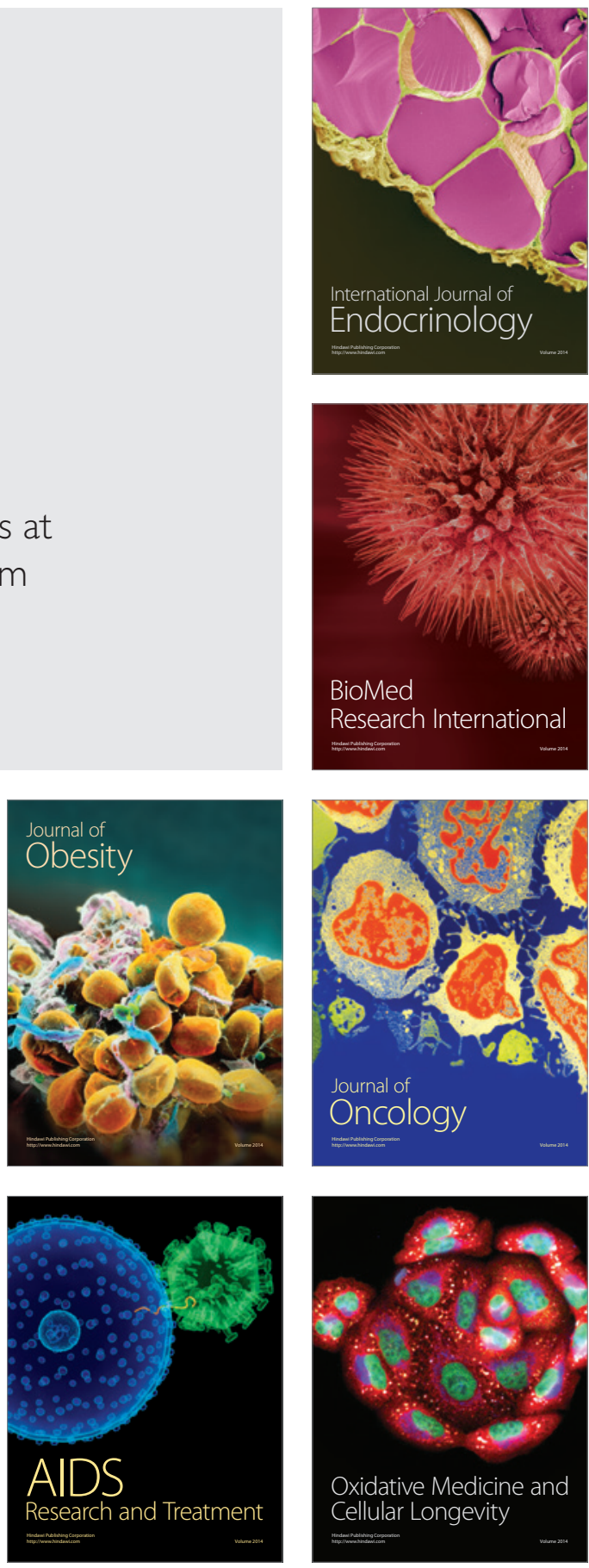